\title{
Correlation analysis of levels of inflammatory cytokines and nitric oxide in peripheral blood with urine proteins and renal function in patients with gestational hypertension
}

\author{
JING-YANG ZHANG $^{1 *}$, XIAO-XIAO CAO $^{1 *}$, HONG-XIA WEN $^{1}$ and HONG-YAN ZHANG ${ }^{2}$ \\ ${ }^{1}$ Department of Cardiac Function, Wuhan Children's Hospital, Tongji Medical College, \\ Huazhong University of Science and Technology, Wuhan, Hubei 430016; ${ }^{2}$ Department of Cardiac Function, \\ Xiangyang Central Hospital (The Affiliated Hospital of Hubei University of Arts and Science) \\ Xiangcheng, Xiangyang, Hubei 441021, P.R. China
}

Received December 22, 2017; Accepted October 10, 2018

DOI: $10.3892 /$ etm.2018.7004

\begin{abstract}
The aim of the study was to investigate correlations among inflammatory cytokines, nitric oxide (NO) level, urine protein, renal function and blood pressure in peripheral blood of patients with hypertensive disorder complicating pregnancy (HDCP). A total of 60 patients diagnosed with HDCP in the Obstetrics Department of Wuhan Children's Hospital, Tongji Medical College, Huazhong University of Science and Technology from May 2016 to April 2017 were selected. The patients were divided into the HDCP $(n=20)$, mild pre-eclampsia $(n=20)$ and severe pre-eclampsia $(n=20)$ groups. Additionally, 20 healthy pregnant women were selected as the control group. General data of the patients were collected. NO, renal function and 24-h urine protein were measured. The systolic and diastolic blood pressure, $\mathrm{C}$-reactive protein (CRP), tumor necrosis factor- $\alpha$ (TNF- $\alpha$ ) and interleukin-6 (IL-6) in the HDCP group was significantly higher than that in the control group. The CRP, TNF- $\alpha$ and IL- 6 levels in the pre-eclampsia groups were higher than those in the gestational hypertension group $(\mathrm{P}<0.05)$. The $\mathrm{NO}$ level in peripheral blood of patients in the pre-eclampsia groups was lower than that in the gestational hypertension group $(\mathrm{P}<0.05)$. The levels of 24-h urine protein, homocysteine (Hcy), cystatin-C (Cys-C), serum creatinine ( $\mathrm{SCr}$ ), urea and $\beta 2$ microglobulin in the preeclampsia groups were higher than those in the gestational
\end{abstract}

Correspondence to: Dr Hong-Yan Zhang, Department of Cardiac Function, Xiangyang Central Hospital (The Affiliated Hospital of Hubei University of Arts and Science), 136 Jingzhou Street, Xiangcheng, Xiangyang, Hubei 441021, P.R. China

E-mail: eti106h@163.com

${ }^{*}$ Contributed equally

Key words: hypertensive disorder complicating pregnancy, inflammatory cytokine, nitric oxide urine protein, renal function hypertension group $(\mathrm{P}<0.05)$. Gestational age and the levels of baseline blood pressure, inflammatory cytokines, 24-h urine protein and renal function have independent predictive value for the occurrence of HDCP $(\mathrm{P}<0.05)$. The results show that, 24-h urine protein, renal function and inflammatory cytokines are closely correlated with the occurrence of HDCP, which can reflect the severity and prognosis of the disease to a certain extent. In addition, it has important reference value for the assessment and treatment of the disease.

\section{Introduction}

One of the most common complications of pregnancy is hypertensive disorder complicating pregnancy (HDCP), and relevant data showed that the incidence rate of it is as high as $\sim 10 \%$, which seriously affects the perinatal survival rate of mothers and children, albeit its pathogenesis remains to be determined (1). Generally, HDCP can be diagnosed by clinical manifestations, urinary protein examination, liver and kidney function examination, and fundus examination; in severe cases, retinal edema, exudation, and hemorrhage, may manifest in the fundus of patients with HDCP (2). Levels of nitric oxide (NO) and inflammatory cytokines represented by C-reactive protein (CRP), tumor necrosis factor- $\alpha$ (TNF- $\alpha$ ) and interleukin-6 (IL-6) in peripheral blood of patients play important roles in the causes of the disease, which promote the occurrence and development of $\operatorname{HDCP}(3,4)$. In patients with HDCP, the most representative laboratory examination is the urine protein examination, which shows urinary tract smooth muscle cell dysfunction, enlarged renal pelvis volume and increased hydronephrosis (5). The excessive activation of inflammatory or other systems lead to immune system disorders and the deposition of an overdose of immune complexes in the kidney, which increase vascular permeability to a certain degree and impair the kidney function, thus leading to the occurrence of proteinuria (6). At the same time, urine proteins are related to the level of blood pressure, so determining the levels of inflammatory factor and NO in peripheral blood is of important significance for the conditions of urine proteins, renal function, and blood pressure, in patients with HDCP (7). 


\section{Patients and methods}

Patients. A total of 60 patients diagnosed with HDCP in the Obstetrics Department of Wuhan Children's Hospital (Wuhan, China) from May 2016 to April 2017 were selected, and were divided into the gestational hypertension $(n=20)$, mild pre-eclampsia $(\mathrm{n}=20)$ and severe pre-eclampsia $(\mathrm{n}=20)$ groups. In addition, 20 healthy pregnant women were selected as the control group. All the included patients were aged 24-33 years, with an average age of $28.72 \pm 5.9$ years; the gestational age was $34-40$ weeks, with an average gestational age of $36.38 \pm 4.2$ weeks. The diagnostic criteria for the included patients with HDCP were based on the 'Chinese Expert Consensus Document on Blood Pressure Management of HDCP' (8), and the staging was specifically conducted according to the level of blood pressure, urine proteins and renal function in patients. All the included patients signed the written informed consent. Inclusion criteria for the study were: patients with high compliance with doctor's advice who co-operated with examinations; patients who were confirmed cases of HDCP; patients aged less than or equal to 36 years; and patients whose fetuses had no obvious defects or diseases. Exclusion criteria were: patients with a history of chronic hypertension disease; patients with a history of cardiovascular system disease; patients with endocrine disease, such as thyroid disease and liver and kidney disease; patients with malignant tumors; patients with severe infection; and patients whose clinical data were incomplete. The study was approved by the Ethics Committee of Wuhan Children's Hospital.

Methods. The clinical data of all patients were retrospectively analyzed, including age, sex, weight, height, delivery times, and gestational age, and the systolic and diastolic blood pressures of all the patients were recorded. Determination of levels of inflammatory cytokines and NO in peripheral blood of patients: After the solid and liquid fasting for $10 \mathrm{~h}$ overnight, $10 \mathrm{ml}$ peripheral blood was extracted, the upper-layer serum was taken, and inflammatory cytokines, CRP, TNF- $\alpha$ and IL-6, were detected using immunoturbidimetry (reagents and instruments provided by Shandong Biological Instrument Co., Ltd., Sandong, China). Determination of $24 \mathrm{~h}$ urine proteins: $24 \mathrm{~h}$ urine was collected and detected using a UniCel Dxl 800 automatic analyzer (Beckman Coulter, Inc., Atlanta, GA, USA). Determination of renal function: $10 \mathrm{ml}$ fasting peripheral venous blood of patients in the morning was extracted, and homocysteine (Hcy), cystatin-C (Cys-C), serum creatinine $(\mathrm{SCr})$, urea and $\beta_{2}$ microglobulin were also detected using a Beckman Coulter UniCel Dxl 800 automatic analyzer.

Statistical analysis. Statistical Product and Service Solutions (SPSS) 19.0 statistical software was used to process data, and the collected data were expressed as means \pm SD. The $\chi^{2}$ test was used to compare the count data. The Pearson correlation analysis was conducted for two factors, and the logistic analysis was performed for related risk factors. $\mathrm{P}<0.05$ indicated that the difference was statistically significant.

\section{Results}

Comparisons of general data between the HDCP and control groups. There were no statistically significant differences in age, body mass index (BMI) and delivery times between the HDCP and control groups $(\mathrm{P}>0.05)$. The systolic and diastolic blood pressures in the HDCP group were significantly higher than those in the control group, but the gestational age of the former was significantly smaller than that of the latter $(\mathrm{P}<0.05)$ (Table I).

Comparisons of levels of inflammatory cytokines in peripheral blood between the HDCP and control groups. Levels of CRP, TNF- $\alpha$ and IL-6 in the HDCP group were significantly higher than those in the control group. Levels of CRP, TNF- $\alpha$ and IL- 6 in the pre-eclampsia groups were higher than those in the gestational hypertension group, and those in the severe pre-eclampsia group were significantly higher than those in the mild pre-eclampsia group. Differences were statistically significant $(\mathrm{P}<0.05)$ (Table II).

Comparison of the NO level in peripheral blood between the HDCP and control group. The NO level in peripheral blood in the HDCP group was significantly lower than that in the control group; levels of $\mathrm{NO}$ in the pre-eclampsia groups were lower than that in the gestational hypertension group, and that in the severe pre-eclampsia group was significantly lower than that in the mild pre-eclampsia group $(\mathrm{P}<0.05)$ (Table III).

Comparisons of levels of $24 \mathrm{~h}$ urine proteins and rental function between the HDCP and control groups. Levels of $24 \mathrm{~h}$ urine proteins, Hcy, Cys-C, SCr, urea and $\beta_{2}$ microglobulin in the HDCP group were significantly higher than those in the control group; those in the pre-eclampsia groups were higher than those in the gestational hypertension group, and those in the severe pre-eclampsia group were significantly higher than those in the mild pre-eclampsia group. Differences were statistically significant $(\mathrm{P}<0.05)$ (Table IV).

Correlation analyses of CRP with $24 \mathrm{~h}$ urine proteins and systolic blood pressure, of $24 \mathrm{~h}$ urine proteins with systolic blood pressure, and of $\mathrm{NO}$ with $24 \mathrm{~h}$ urine proteins. In peripheral blood of the included patients, the level of CRP was positively associated with 24-h urine proteins $(\mathrm{r}=0.792, \mathrm{P}<0.001)$ and the systolic blood pressure $(r=0.996, P<0.001)$, and $24-h$ urine proteins were positively correlated with the systolic blood pressure $(r=0.795$, $\mathrm{P}<0.001$ ), but the level of $\mathrm{NO}$ in peripheral blood was negatively related to $24 \mathrm{~h}$ urine proteins $(\mathrm{r}=-0.722, \mathrm{P}<0.001)$ (Figs. 1-4).

Logistic analysis of the prediction of risk factors for the occurrence of HDCP in women during the gestation period. The level of basic blood pressure (systolic blood pressure, $\mathrm{P}=0.016$; diastolic blood pressure, $\mathrm{P}=0.005)$, gestational age $(\mathrm{P}=0.001)$ and the levels of inflammatory cytokines (TNF- $\alpha, P=0.039$; IL-6, $\mathrm{P}=0.025$; CRP, $\mathrm{P}=0.022$; NO, $\mathrm{P}=0.024), 24 \mathrm{~h}$ urinary proteins $(0.001)$ and renal function $(\mathrm{Hcy}, \mathrm{P}=0.032$; Cys- $\mathrm{C}$, $\mathrm{P}=0.029$; $\mathrm{SCr}, \mathrm{P}=0.018$; Urea, $\mathrm{P}=0.013 ; \beta_{2}$ microglobulin, $\mathrm{P}=0.036$ ) had independent predictive values for the occurrence of HDCP $(\mathrm{P}<0.05)($ Table V).

\section{Discussion}

Concerning the health risks of perinatal pregnant women and fetuses, HDCP exerts serious impacts on their health, 
Table I. Comparisons of general data between the HDCP group and the control group.

\begin{tabular}{|c|c|c|c|c|c|c|c|}
\hline Group & $\mathrm{n}$ & $\begin{array}{c}\text { Age } \\
\text { (years old) }\end{array}$ & $\begin{array}{c}\text { BMI } \\
\left(\mathrm{kg} / \mathrm{m}^{2}\right)\end{array}$ & $\begin{array}{l}\text { Delivery times } \\
\text { (time) }\end{array}$ & $\begin{array}{c}\text { Systolic blood } \\
\text { pressure }(\mathrm{mmHg})\end{array}$ & $\begin{array}{c}\text { Diastolic blood } \\
\text { pressure }(\mathrm{mmHg})\end{array}$ & $\begin{array}{c}\text { Gestational age } \\
\text { (week) }\end{array}$ \\
\hline HDCP group & 60 & $30.53 \pm 4.8$ & $29.35 \pm 4.2$ & $1.6 \pm 0.7$ & $169.3 \pm 18.5$ & $104.7 \pm 9.9$ & $35.1 \pm 3.7$ \\
\hline Control group & 20 & $28.79 \pm 5.1$ & $28.76 \pm 3.9$ & $1.4 \pm 0.9$ & $136.7 \pm 14.8$ & $88.3 \pm 8.7$ & $37.9 \pm 3.1$ \\
\hline P-value & & 0.351 & 0.096 & 0.812 & 0.001 & 0.001 & 0.023 \\
\hline
\end{tabular}

HDCP, hypertensive disorder complicating pregnancy; BMI, body mass index.

Table II. Comparisons of levels of inflammatory cytokines between the HDCP group and the control group.

\begin{tabular}{lcccr}
\hline Group & $\mathrm{n}$ & TNF- $\alpha(\mathrm{pg} / \mathrm{ml})$ & IL-6 (ng/l) & CRP $(\mathrm{mg} / \mathrm{l})$ \\
\hline HDCP group & 60 & $14.38 \pm 4.21$ & $17.58 \pm 2.23$ & $8.93 \pm 1.45$ \\
Gestational hypertension group & 20 & $12.73 \pm 3.93$ & $15.95 \pm 1.12$ & $6.40 \pm 0.81$ \\
Mild preeclampsia group & 20 & $14.26 \pm 5.01$ & $16.88 \pm 2.84$ & $7.51 \pm 0.89$ \\
Severe preeclampsia group & 20 & $15.67 \pm 4.42$ & $19.06 \pm 2.57$ & $10.96 \pm 1.88$ \\
Control group & 20 & $9.53 \pm 2.38$ & $8.59 \pm 1.18$ & $2.82 \pm 1.73$ \\
P-value & & 0.001 & 0.001 & $<0.001$
\end{tabular}

HDCP, hypertensive disorder complicating pregnancy; TNF- $\alpha$, tumor necrosis factor- $\alpha$; IL-6, interleukin-6; CRP, C-reactive protein.

Table III. Comparison of the NO level between the HDCP group and the control group.

\begin{tabular}{lcc}
\hline Group & $\mathrm{n}$ & $\mathrm{NO}(\mu \mathrm{mmol} / \mathrm{l})$ \\
\hline HDCP group & 60 & $29.02 \pm 5.08$ \\
Gestational hypertension group & 20 & $31.39 \pm 4.54$ \\
Mild preeclampsia group & 20 & $28.82 \pm 4.03$ \\
Severe preeclampsia group & 20 & $23.92 \pm 2.18$ \\
Control group & 20 & $45.21 \pm 5.15$ \\
P-value & & $<0.001$ \\
\hline
\end{tabular}

HDCP, hypertensive disorder complicating pregnancy; NO, nitric oxide.

but there is no unified conclusion on the pathogenesis of HDCP (9). There is an increasing number of studies on HDCP, which aim to identify optimal early prevention or treatment methods (10). It is generally believed in clinical practice that HDCP is caused by the combined actions of immune system dysfunction, shallow placental implantation, smooth muscle, and cell dysfunction (11), and the most representative laboratory examinations are the examinations of $24 \mathrm{~h}$ urine protein in urine and renal function in peripheral blood (12). NO plays a very important role in the injury and recovery processes of vascular endothelial cells. NO is capable of dilating blood vessels (13), and the reduced NO content in the body represents severe vascular endothelial damages. Sufficient NO can be synthesized and released within the body of normal healthy pregnant women during the gestation period to maintain placental blood circulation and repair vascular endothelial

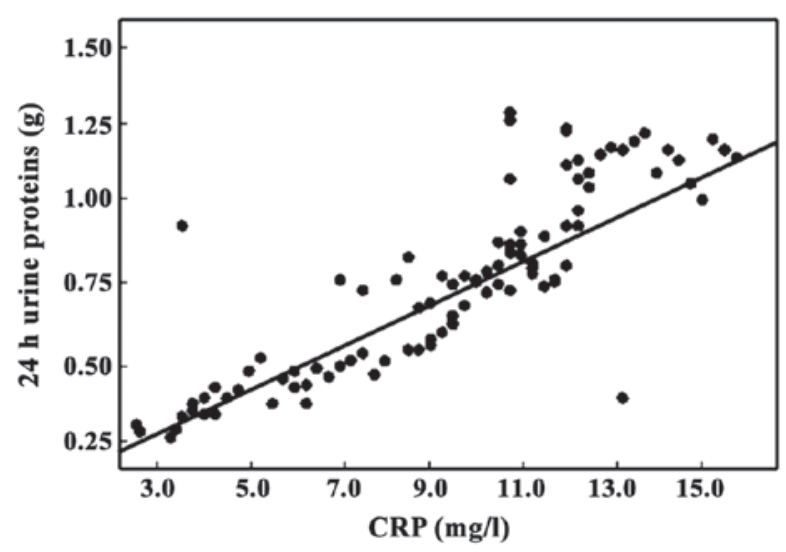

Figure 1. Correlation between CRP and $24 \mathrm{~h}$ urine proteins. CRP, C-reactive protein.

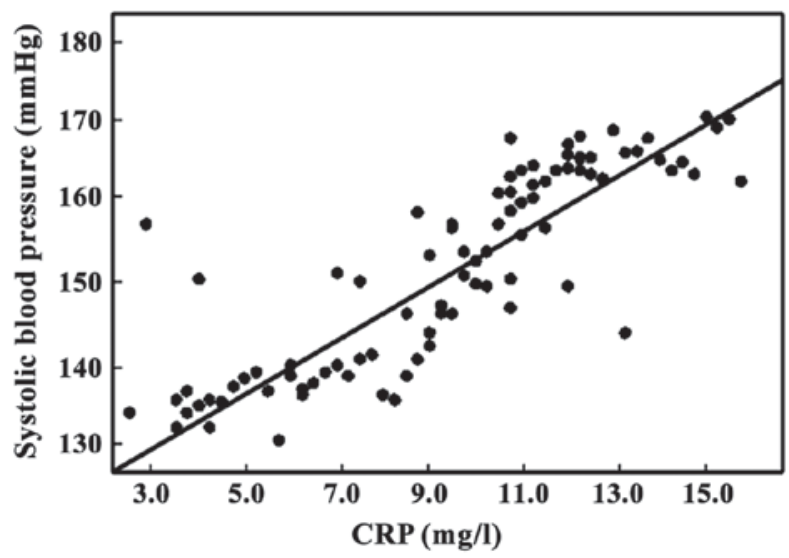

Figure 2. Correlation between CRP and the systolic blood pressure. CRP, C-reactive protein. 
Table IV. Comparisons of levels of $24 \mathrm{~h}$ urine proteins and rental function between the HDCP group and the control group.

\begin{tabular}{|c|c|c|c|c|c|c|c|}
\hline Group & $\mathrm{n}$ & $\begin{array}{c}24 \mathrm{~h} \text { urine protein } \\
(\mathrm{g} / 24 \mathrm{~h})\end{array}$ & $\begin{array}{c}\text { Hcy } \\
(\mu \mathrm{mmol} / \mathrm{l})\end{array}$ & $\begin{array}{c}\text { Cys-C } \\
(\mu \mathrm{mmol} / \mathrm{l})\end{array}$ & $\begin{array}{c}\mathrm{SCr} \\
(\mu \mathrm{mmol} / \mathrm{l})\end{array}$ & $\begin{array}{c}\text { Urea } \\
(\mathrm{mmmol} / \mathrm{l})\end{array}$ & $\begin{array}{c}\beta_{2} \text { microglobulin } \\
(\mathrm{mg} / \mathrm{l})\end{array}$ \\
\hline HDCP group & 60 & $1.07 \pm 0.66$ & $16.53 \pm 2.26$ & $1.37 \pm 0.29$ & $49 \pm 12$ & $4.4 \pm 0.8$ & $3.5 \pm 1.4$ \\
\hline Gestational hypertension group & 20 & $0.63 \pm 0.19$ & $14.77 \pm 2.21$ & $1.15 \pm 0.44$ & $46 \pm 12$ & $4.1 \pm 0.6$ & $3.3 \pm 0.9$ \\
\hline Mild preeclampsia group & 20 & $0.94 \pm 0.28$ & $17.59 \pm 3.30$ & $1.49 \pm 0.36$ & $52 \pm 10$ & $4.6 \pm 0.8$ & $3.5 \pm 1.3$ \\
\hline Severe preeclampsia group & 20 & $2.63 \pm 0.57$ & $21.38 \pm 3.38$ & $3.03 \pm 0.58$ & $68 \pm 13$ & $5.8 \pm 0.9$ & $4.4 \pm 0.5$ \\
\hline Control group & 20 & $0.10 \pm 0.09$ & $8.96 \pm 2.27$ & $0.97 \pm 0.18$ & $39 \pm 5$ & $3.0 \pm 0.6$ & $2.8 \pm 0.2$ \\
\hline P-value & & 0.001 & 0.001 & $<0.001$ & 0.001 & 0.001 & $<0.001$ \\
\hline
\end{tabular}

HDCP, hypertensive disorder complicating pregnancy. Hcy, homocysteine; Cys-C, cystatin-C; $\mathrm{SCr}$, serum creatinine.

Table V. Logistic analysis of the prediction of risk factors for the occurrence of HDCP in women during the gestation period.

\begin{tabular}{|c|c|c|c|}
\hline Factor & P-value & $\begin{array}{c}\text { Odds } \\
\text { ratio }(\mathrm{OR}) \\
\text { value }\end{array}$ & $\begin{array}{c}95 \% \\
\text { confidence } \\
\text { interval } \\
(95 \% \mathrm{CI})\end{array}$ \\
\hline Age & 0.108 & 1.094 & $0.988-1.157$ \\
\hline BMI & 0.847 & 0.910 & $0.102-6.826$ \\
\hline Delivery times & 0.526 & 1.448 & $0.465-4.987$ \\
\hline Systolic blood pressure & 0.016 & 7.955 & $1.918-26.165$ \\
\hline Diastolic blood pressure & 0.005 & 7.347 & $1.919-22.159$ \\
\hline Gestational age & 0.044 & 1.029 & $0.955-1.118$ \\
\hline TNF- $\alpha$ & 0.039 & 1.001 & 0.927-1.019 \\
\hline IL-6 & 0.025 & 1.432 & $0.576-3.572$ \\
\hline CRP & 0.022 & 2.654 & $0.964-7.117$ \\
\hline NO & 0.024 & 1.047 & 0.996-1.312 \\
\hline $24 \mathrm{~h}$ urine protein & 0.001 & 1.005 & $0.997-1.033$ \\
\hline Hcy & 0.032 & 1.065 & $0.959-1.115$ \\
\hline Cys-C & 0.029 & 1.054 & $0.984-1.065$ \\
\hline $\mathrm{SCr}$ & 0.018 & 1.006 & 0.974-1.082 \\
\hline Urea & 0.013 & 7.543 & $1.918-18.747$ \\
\hline$\beta_{2}$ microglobulin & 0.036 & 1.017 & 0.954-1.119 \\
\hline
\end{tabular}

HDCP, hypertensive disorder complicating pregnancy; BMI, body mass index; TNF- $\alpha$, tumor necrosis factor-Hcy, homocysteine; Cys-C, cystatin-C; SCr, serum creatinine; IL-6, interleukin-6; CRP, C-reactive protein; Hcy, homocysteine; Cys-C, cystatin- $\mathrm{C}$; $\mathrm{SCr}$, serum creatinine

injury $(14,15)$. If the content of NO is decreased, the vascular pressure is increased due to vasoconstriction, vascular endothelial damage and other factors (16), which is consistent with the conclusion of this study, i.e., that the level of NO in peripheral blood of patients in the HDCP group was significantly decreased compared with that in the control group.

Inflammatory cytokines also promote the occurrence and development of HDCP. Normal endometrium and placenta contain a certain amount of macrophages that are important cells for the synthesis and secretion of TNF- $\alpha$ (17). TNF- $\alpha$

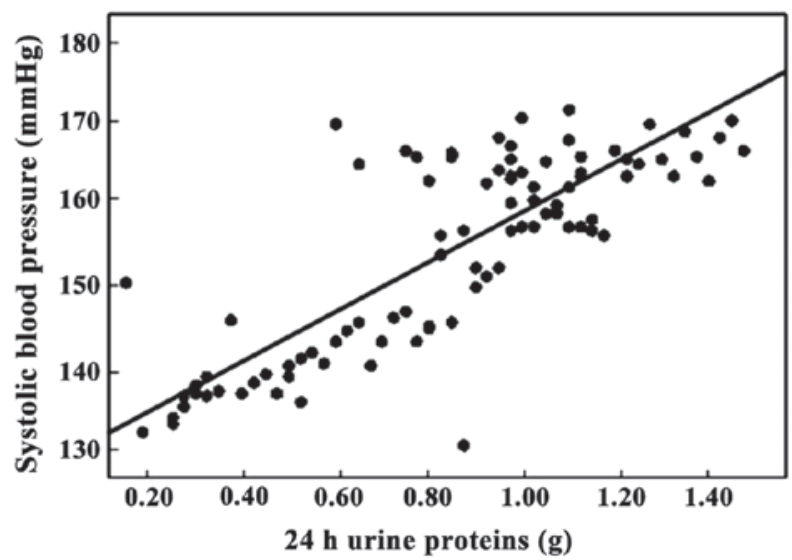

Figure 3. Correlation between $24 \mathrm{~h}$ urine proteins and the systolic blood pressure.

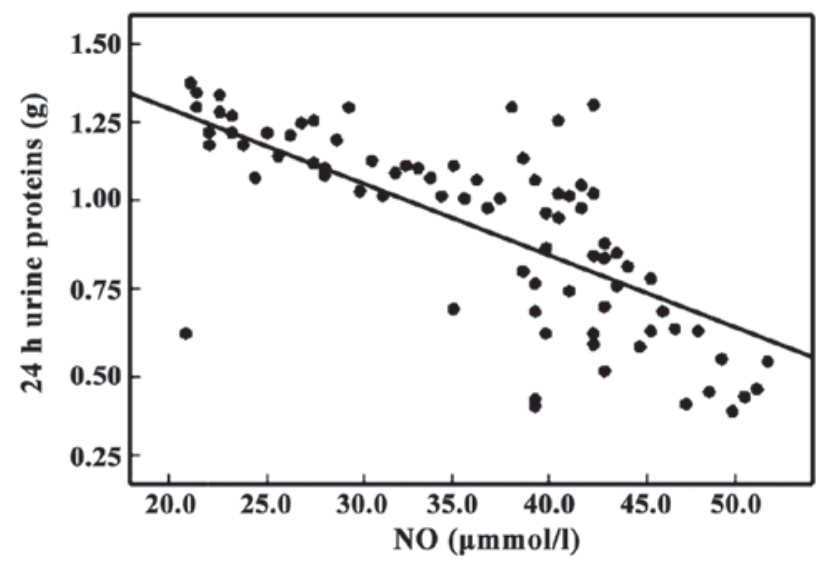

Figure 4. Correlation between NO and $24 \mathrm{~h}$ urine proteins. NO, nitric oxide.

can maintain normal pregnancy and resist the occurrence of various types of cancer including prostate cancer, ovarian cancer and infections to a certain degree (18-20). However, if the content of the synthesized and secreted TNF- $\alpha$ in vivo is too high, vascular endothelial cells are injured through, for example, the oxidation of free radicals, and arteries excessively contract, thus leading to HDSP or exacerbating the disease (21). Many kinds of tissue cells in the human body 
can produce IL-6, which has many functions, such as regulating the immune system. Abnormal secretion can lead to excessive accumulation of platelets in blood vessels and form endothelial cell dysfunction (22). In addition, the level of CRP in the normal human body is very low, but under infection, inflammatory reactions, the level of CRP will be rapidly increased; thus, CRP is a sensitive indicator of inflammatory response (23). The level of CRP in peripheral blood of women with HDCP is higher than that in healthy pregnant women, because the overaction of the inflammatory system damages the vascular endothelium and increases the blood pressure (24). The findings of this study showed that, levels of inflammatory cytokines in peripheral blood of patients in the HDCP group were significantly higher than those in the control group, and the differences were statistically significant $(\mathrm{P}<0.05)$. Furthermore, inflammatory cytokines were positively correlated with urine proteins and systolic blood pressure, indicating that inflammatory cytokines can reflect the severity of the disease to a certain degree.

Generally, renal function is represented by levels of Hcy, Cys- $C$, SCr, urea and $\beta_{2}$ microglobulin, which are also used to reflect the severity of kidney dysfunction. In patients with HDCP, the expressions of renal function indexes are different at different stages of the disease, that is, the expression level is increased with the development of the disease (22). In this study, levels of $24 \mathrm{~h}$ urine protein, Hcy, Cys-C, SCr, urea and $\beta_{2}$ microglobulin in the HDCP group were significantly higher than those in the control group, those in the pre-eclampsia groups were higher than those in the gestational hypertension group, and those in the severe pre-eclampsia group were significantly higher than those in the mild pre-eclampsia group, which were consistent with the results of many current studies, as previously indicated. Therefore, 24 -h urine proteins and renal function in patients with HDCP change with the disease, and at the same time, levels of inflammatory cytokines and $\mathrm{NO}$ in peripheral blood of patients are closely correlated with the occurrence and development of the disease. Timely detection of the above indexes provides more valuable references for the treatment of patients with HDCP.

\section{Acknowledgements}

Not applicable.

\section{Funding}

No funding was received.

\section{Availability of data and materials}

The datasets used and/or analyzed during the current study are available from the corresponding author on reasonable request.

\section{Authors' contributions}

JYZ and XXC were responsible for inflammatory cytokines and renal function analysis. HXW and HYZ collected and analyzed the general data of patients. All authors read and approved the final manuscript.

\section{Ethics approval and consent to participate}

The study was approved by the Ethics Committee of Wuhan Children's Hospital (Wuhan, China). All the included patients signed the written informed consent

\section{Patient consent for publication}

Not applicable.

\section{Competing interests}

The authors declare that they have no competing interests.

\section{References}

1. Reilly MP, Rohatgi A, McMahon K, Wolfe ML, Pinto SC, Rhodes T, Girman C and Rader DJ: Plasma cytokines, metabolic syndrome, and atherosclerosis in humans. J Investig Med 55: 26-35, 2007.

2. Magyar MT, Bereczki D, Csípo I, Gyimesi E, Csiba L, Valikovics A, Balla J and Sipka S: Elevated white blood cell count, CRP and fibrinogen levels are not associated with increased anti-endothelial and anti-ox-LDL antibody, MCP-1, and RANTES levels in early onset occlusive carotid artery disease. Cytokine 37: 44-50, 2007.

3. Thomas GN, Critchley JAJH, Tomlinson B, Cockram CS and Chan JC: Peripheral vascular disease in Type 2 diabetic Chinese patients: Associations with metabolic indices, concomitant vascular disease and genetic factors. Diabet Med 20: 988-995, 2003.

4. Paul MR, Meir JS and Nader R: Study on the correlation between renal hemodynamics and endothelial function in hypertensive patients. JAMA 285: 2481-2485, 2001.

5. Thakore AH, Guo CY, Larson MG, Corey D, Wang TJ, Vasan RS, D'Agostino RB Sr, Lipinska I, Keaney JF Jr, Benjamin EJ, et al: Association of multiple inflammatory markers with carotid intimal medial thickness and stenosis (from the Framingham Heart Study). Am J Cardiol 99: 1598-1602, 2007.

6. Isidro ML and Ruano B: Bone disease in diabetes. Curr Diabetes Rev 6: 144-155, 2010.

7. Kanazawa I, Yamaguchi T, Hayashi K, Takase H, Shimizu T and Sugimoto T: Effects of treatment with risedronate and alfacalcidol on progression of atherosclerosis in postmenopausal women with type 2 diabetes mellitus accompanied with osteoporosis. Am J Med Sci 339: 519-524, 2010.

8. Niu V, Xu Y, Hao J, Van S, Huang K, Pan W, Ge X, Liu G, Huang S and Tao F: Prepregnancy body mass index, gestational weight gain and hypertensive disorder complicating pregnancy: A prospective cohort study in Ma'anshan City. Wei Sheng Yan Jiu 45: 205-210, 2016 (In Chinese).

9. Wada S, Kamiya S and Fukawa T: The relationship between proteinuria and inflammatory factors in patients with severe pre-eclampsia. Clin Calcium 18: 600-605, 2008.

10. Siddappa R, Mulder W, Steeghs I, van de Klundert C, Fernandes H, Liu J, Arends R, van Blitterswijk C and de Boer J: cAMP/PKA signaling inhibits osteogenic differentiation and bone formation in rodent models. Tissue Eng Part A 15: 2135-2143, 2009.

11. Wan SM, Yu YH, Huang YY and Su GD: Morbidity regularity of severe complications of hypertensive disorder complicating pregnancy in clinics. Zhonghua Fu Chan Ke Za Zhi 42: 510-514, 2007 (In Chinese).

12. Pittas AG, Lau J and Hu FB: The clinical significance of urine protein and urine creatinine ratio detection. Clin Endocrinol Metab 92: 3017-3026, 2007.

13. Takagi M, Kasayama S, Yamamoto T, Motomura T, Hashimoto K, Yamamoto H, Sato B, Okada S and Kishimoto T: Advanced glycation endproducts stimulate interleukin-6 production by human bone-derived cells. J Bone Miner Res 12: 439-446, 1997.

14. Liu E, Meigs JB, Pittas AG, Economos CD, McKeown NM, Booth SL and Jacques PF: Predicted 25-hydroxy vitamin D score and incident type 2 diabetes in the Framingham Offspring Study. Am J Clin Nutr 91: 1627-1633, 2010 
15. Asanuma Y, Chung CP, Oeser A, Solus JF, Avalos I, Gebretsadik T, Shintani A, Raggi P, Sokka T, Pincus T, et al: Serum osteoprotegerin is increased and independently associated with coronary-artery atherosclerosis in patients with rheumatoid arthritis. Atherosclerosis 195: e135-e141, 2007.

16. Hofbauer LC, Khosla S, Dunstan CR, Lacey DL, Boyle WJ and Riggs BL: The roles of osteoprotegerin and osteoprotegerin ligand in the paracrine regulation of bone resorption. $\mathrm{J}$ Bone Miner Res 15: 2-12, 2000.

17. Haas M, Leko-Mohr Z, Roschger P, Kletzmayr J, Schwarz C, Domenig C, Zsontsich T, Klaushofer K, Delling G and Oberbauer R: Osteoprotegerin and parathyroid hormone as markers of high-turnover osteodystrophy and decreased bone mineralization in hemodialysis patients. Am J Kidney Dis 39: 580-586, 2002

18. Carpentier PA, Dingman AL and Palmer TD: Placental TNF- $\alpha$ signaling in illness-induced complications of pregnancy. Am J Pathol 178: 2802-2810, 2011.

19. Charles KA, Kulbe H, Soper R, Escorcio-Correia M,Lawrence T, Schultheis A, Chakravarty P, Thompson RG, Kollias G, Smyth JF, et al: The tumor-promoting actions of TNF-alpha involve TNFR1 and IL-17 in ovarian cancer in mice and humans. J Clin Invest 119: 3011-3023, 2009.
20. Pirtskhalaishvili G, Shurin GV, Esche C, Trump DL and Shurin MR: TNF-alpha protects dendritic cells from prostate cancer-induced apoptosis. Prostate Cancer Prostatic Dis 4: 221-227, 2001.

21. Malyszko J, Malyszko JS, Wolczynski S and Mysliwiec M: Osteoprotegerin and its correlations with new markers of bone formation and bone resorption in kidney transplant recipients. Transplant Proc 35: 2227-2229, 2003.

22. KeDy DJ: Wilkinson Berka JL and Ricardo SD: Management of Chinese consensus for pregnant hypertension patients. Nephrol Dial Transplant 17: 985-991, 2002.

23. Hullinger TG, Pan Q, Viswanathan HL and Somerman MJ: TGFbeta and BMP-2 activation of the OPN promoter: Roles of smad- and hox-binding elements. Exp Cell Res 262: 69-74, 2001.

24. Yuan T, Zhang T and Han Z: Placental vascularization alterations in hypertensive disorders complicating pregnancy (HDCP) and small for gestational age with HDCP using three-dimensional power doppler in a prospective case control study. BMC Pregnancy Childbirth 15: 240, 2015

This work is licensed under a Creative Commons Attribution-NonCommercial-NoDerivatives 4.0 International (CC BY-NC-ND 4.0) License. 